\title{
Calcified amorphous tumor in the aortic valve identified by computed tomography
}

\author{
Yutaka Koyama, MD, ${ }^{\mathrm{a}}$ Satoshi Tsujimoto, $\mathrm{MD},{ }^{\mathrm{b}}$ and Masanori Yamamoto, $\mathrm{MD}^{\mathrm{b}, \mathrm{c}}$
}

\footnotetext{
From the Departments of a Cardiovascular Surgery and ${ }^{\mathrm{b}}$ Cardiology, Nagoya Heart Center, Nagoya, Japan; and ${ }^{\mathrm{c}}$ Department of Cardiology, Toyohashi Heart Center, Toyohashi, Japan.

Disclosures: Y.K. is a proctor for transapical-TAVI for the Edwards SAPIEN valve. M.Y. is a proctor for transfemoral-TAVI for the Edwards SAPIEN valve and for the Medtronic CoreValve. All other authors have nothing to disclose with regard to commercial support.

Received for publication April 3, 2019; revisions received April 17, 2019; accepted for publication April 18, 2019; available ahead of print June 12, 2019.

Address for reprints: Yutaka Koyama, MD, Department of Surgery, Nagoya Heart Center, Nagoya, Japan (E-mail: ykoyama@heart-center.or.jp or yutatako2000@mac.com).

J Thorac Cardiovasc Surg 2020;159:e161-3

$0022-5223 / \$ 36.00$

Copyright $(C) 2019$ by The American Association for Thoracic Surgery

https://doi.org/10.1016/j.jtcvs.2019.04.094
}

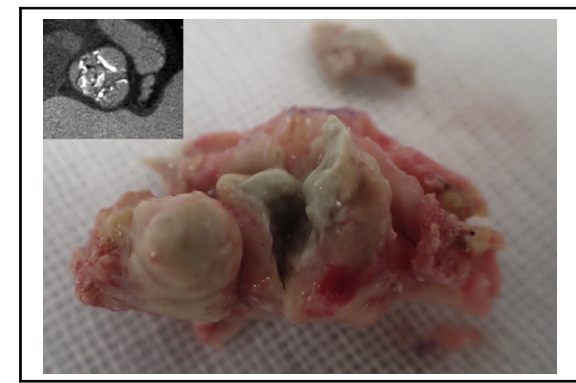

Cross-sectional image by multidetector computed tomography and resected specimen of CAT in the aortic valve.

Central Message
Careful interpretation via multidetector
computed tomography is recommended, and
caution should be exercised because of possible
existence of CAT in the aortic valve that can
mimic degenerative aortic valve stenosis
when considering TAVR.

See Commentary on page e165.
An 83-year-old woman was referred to Nagoya Heart Center for symptomatic aortic valve stenosis. Transthoracic echocardiography revealed severe aortic valve stenosis without other abnormal findings (Figure 1, A). Considering the patient's advanced age, our cardiology team decided that she would be a candidate for transcatheter aortic valve replacement (TAVR). However, prescreening multidetector computed tomography showed an unusual image with an encapsulated mass between the noncoronary cusp (NCC) and the left coronary cusp (Figure 1, B, Video 1). Although this mass could not be diagnosed accurately, it appeared to be a possible cause for systemic embolization due to compression by the transcatheter heart valve. Therefore, we switched to a surgical approach. Surgical inspection

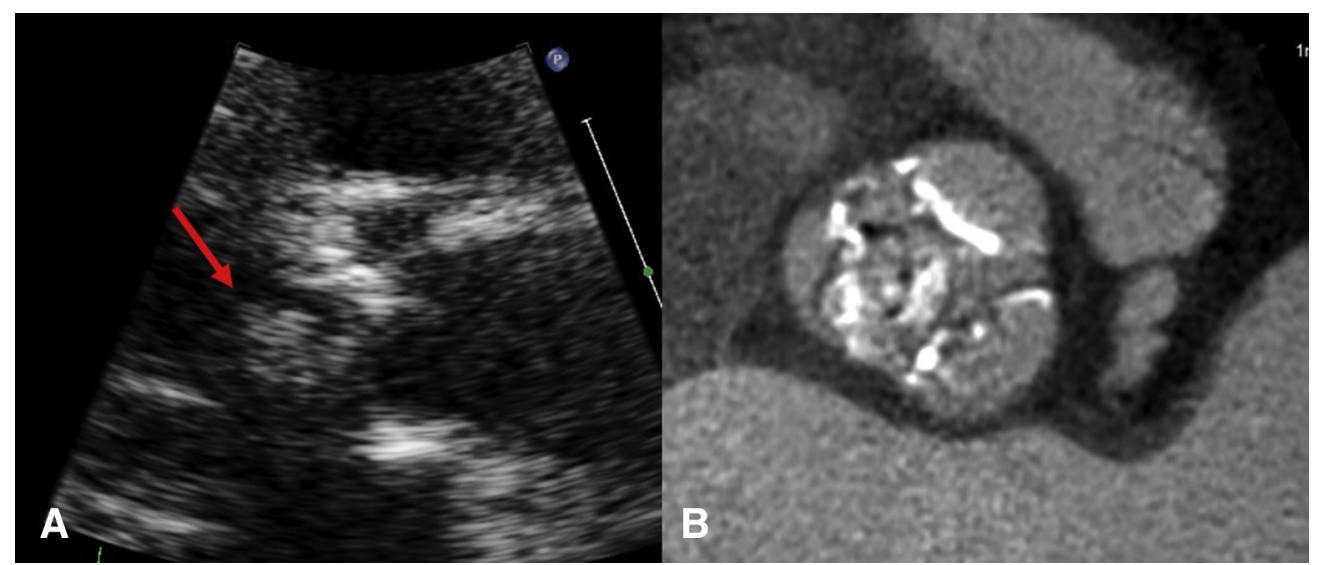

FIGURE 1. A, Transthoracic echocardiography finding showed leaflet thickening (red arrow) in the aortic valves. B, Cross-sectional image of the aortic valve by multidetector computed tomography identified encapsulated mass. C, Surgical finding of the aortic valve (red asterisk: NCC). D, Viscous contents (blue arrow) ruptured from inside the NCC. E, Resected specimen of the aortic valve (red arrow: encapsulated mass in the NCC). F, Histopathology of amorphous mass showing calcified caseous necrosis with no cellular components. 


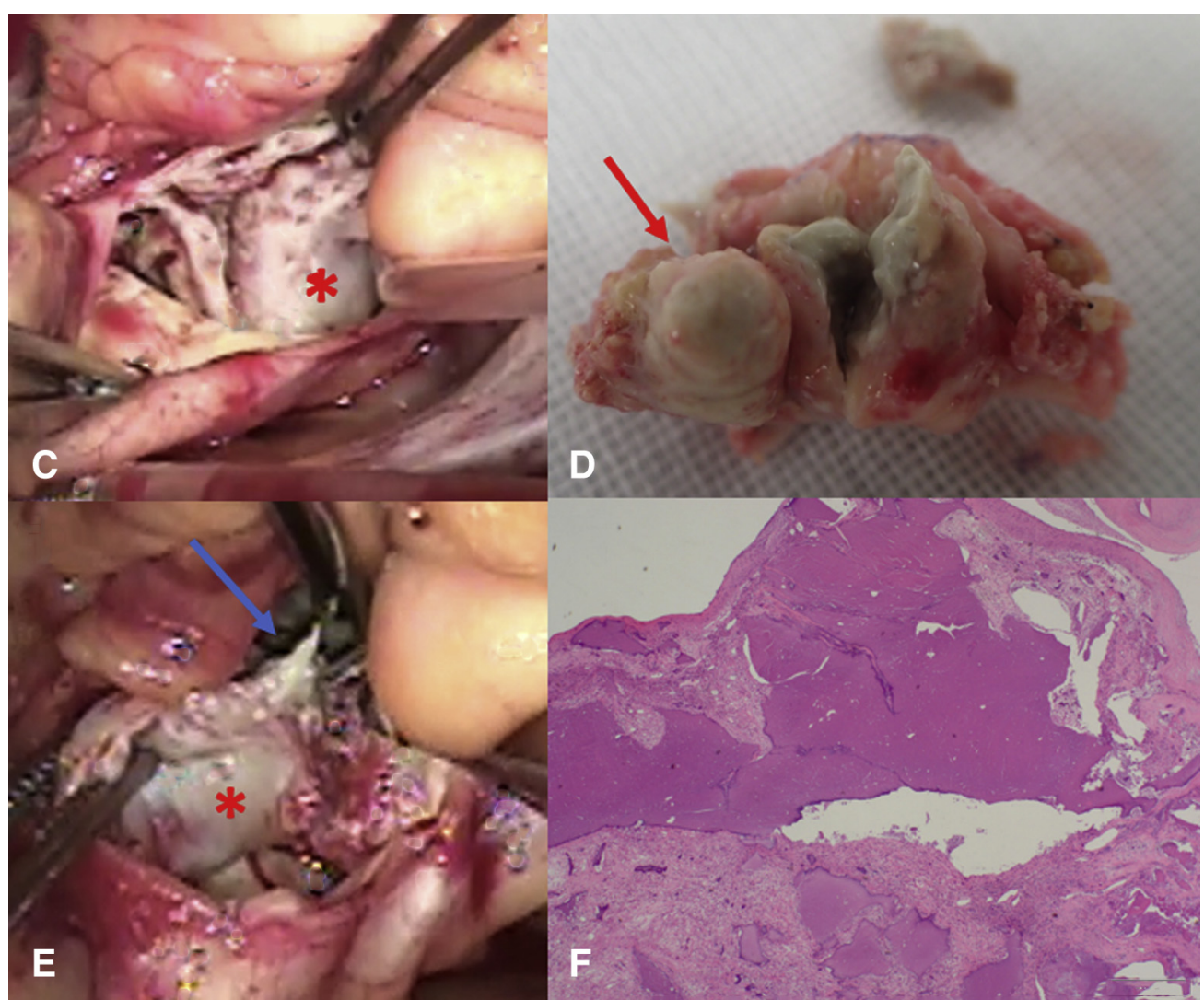

FIGURE 1. (Continued).

showed that the NCC had proliferated more than the other cusp (Figure 1, $C$, Video 2). The viscous contents were drained from the encapsulated mass inside the resected NCC (Figure 1, D). A portion of this tissue was found to protrude into the left ventricle (Figure 1, E). Histopathologic examination of the amorphous mass revealed calcified caseous nodules of the NCC in contrast to only degenerative changes in the other cusps (Figure 1,F). The final

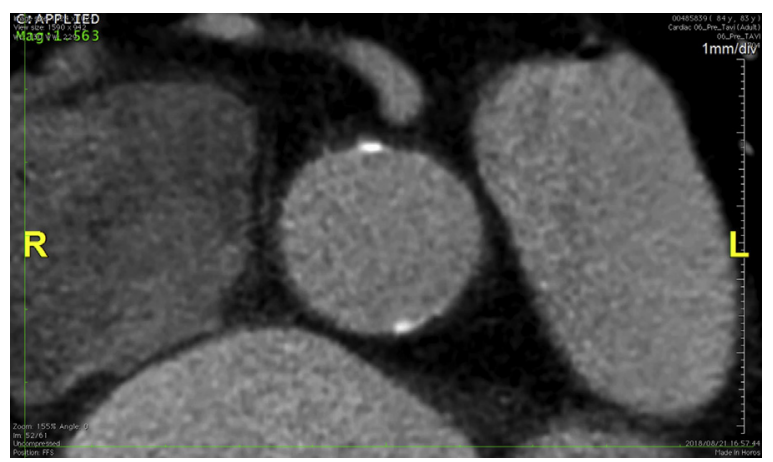

VIDEO 1. Cross-sectional image of the aortic root by multidetector computed tomography identified encapsulated mass. Video available at: https://www.jtcvs.org/article/S0022-5223(19)31033-5/fulltext. pathological diagnosis was calcified amorphous tumor (CAT).

CAT in the aortic valve is a rare non-neoplastic intracardiac tumor $^{1-3}$ and a mobile mass that may protrude as several caseous nodules after TAVR. To avoid systemic distal embolism, complete surgical excision, and not TAVR, is recommended for patients with this condition. Careful interpretation via multidetector computed tomography will help diagnose CAT with

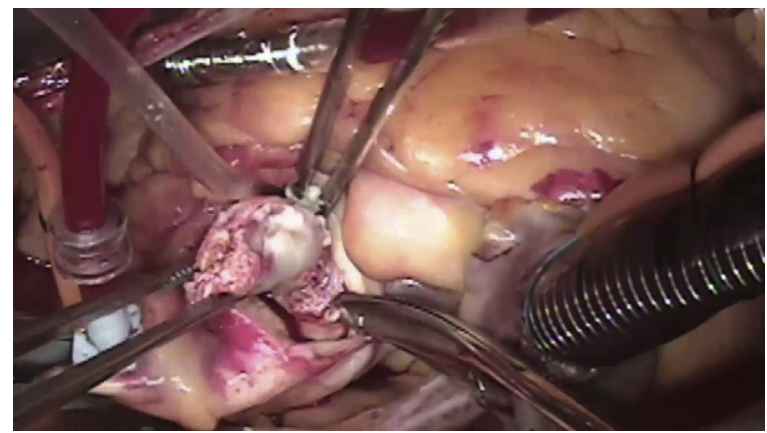

VIDEO 2. Surgical view showed that the NCC was bulkier than the other cusps and viscous contents ruptured from inside the NCC. Video available at: https://www.jtcvs.org/article/S0022-5223(19)31033-5/fulltext. 
isolated and "capsulized" image. When considering TAVR, caution should be exercised because of possible existence of CAT in the aortic valve.

The authors thank Dr H. Ueda from National Cerebral and Cardiovascular Center for providing carefully considered feedback and valuable comments.

\section{References}

1. Reynolds C, Tazelaar HD, Edwards WD. Calcified amorphous tumor of the hear (cardiac CAT). Hum Pathol. 1997;28:601-6.

2. Fujiwara M, Watanabe H, Iino T, Kobukai Y, Ishibashi K, Yamamoto H, et al. Two cases of calcified amorphous tumor mimicking mitral valve vegetation. Circulation. 2012;125:e432-4.

3. Kasai M, Osako M, Tanino T, Maeshima A. A calcified amorphous tumor originating in the aortic valve cusp. Ann Thorac Surg. 2018;105:e235-7. 